Historic, archived document

Do not assume content reflects current scientific knowledge, policies, or practices. 



\title{
$53112 \%$
}

\section{AN IMPROVED TYPE OF PRESSURE TESTER FOR THE DETERMINATION OF FRUIT MATURITY}

\author{
J. R. MAGNESS 1 \\ Physiologist \\ and \\ GEORGE F. TAYLOR \\ Associate Biophysicist
}

Office of Horticultural Investigations, Bureau of Plant Industry

\section{CONTENTS}

\begin{tabular}{r|c} 
Page & \\
1 & Effect of testing with and without \\
peel removed & Influence of rate of application of \\
2 & pressure on pressure-test results \\
3 & Range of pressures in apples as \\
3 & tested by this type of equipment_-- \\
5 & .
\end{tabular}

Introduction

The pressure test as a measure of maturity

Description of th

Details of manufacture

Essentials of manufacture

Use of the pressure tester on apples_

\begin{tabular}{|c|c|}
\hline \multicolumn{2}{|c|}{ CONTENTS } \\
\hline Page & \\
\hline 1 & $\begin{array}{l}\text { Effect of testing with and without } \\
\text { peel removed }\end{array}$ \\
\hline $\begin{array}{l}2 \\
3 \\
3 \\
5 \\
5\end{array}$ & $\begin{array}{l}\text { Influence of rate of application of } \\
\text { pressure on pressure-test results } \\
\text { Range of pressures in apples as } \\
\text { tested by this type of equipment.- }\end{array}$ \\
\hline
\end{tabular}

\section{INTRODUCTION}

The determination of maturity in fruit is one of the most difficult problems which the grower and handler must meet. The condition of the fruit as to degree of maturity when it is removed from the tree largely determines its dessert quality as well as its storage or transportation possibilities. This factor of picking maturity is of special importance with such fruits as peaches, plums, pears, and apricots, which have a short shipping or storage life at best and vary greatly in quality, depending upon the degree of maturity reached when picked. Allowing the fruit to become too mature on the tree results in a product which will not carry through to market, whereas picking the fruit in a too immature condition results in an almost inedible product. There is great need of definite picking standards for such fruits which will allow them to be left on the tree as long

1 The writers wish to express their appreciation of assistance rendered by H. C. Diehl and M. H. Haller, Junior Physiologists, in testing this instrument, and to R. E. Newton, mechanic, for many valuable suggestions. A. F. Wahlstrom made the drawings. Others of the Bureau of Plant Industry from time to time made helpful suggestions and c riticisms. 
as possible and at the same time assure their carrying through to market in satisfactory condition.

Of equally great importance, especially with such fruits as apples and winter pears, which have a long storage or holding season, is the determination of what may be termed "storage maturity." This consists in the determination of the condition of the fruit between the time of its removal from the tree and its ultimate consumption. During this period the fruit undergoes a marked ripening process. The texture of the flesh changes from firm or hard to soft and mealy, accompanied by changes in the chemical composition of the fruit and oftentimes by changes in the color and appearance of the skin.

In the case of apples and winter pears certain terms, such as "hard," "firm," "ripe," "soft ripe," "dead ripe," or "overripe," have been used to signify various stages of storage maturity. Whether a certain lot of apples or pears falls into one class or the other has been a matter of personal judgment. This has led to confusion and to differences of opinion, which have often resulted in rejections of shipments or adjustments of prices in the commercial trade. These differences of opinion and the general uncertainty regarding maturity standards indicate the necessity of some test for maturity in fruits aside from the unsupported judgment of an individual.

\section{THE PRESSURE TEST AS A MEASURE OF MATURITY}

The most outstanding characteristic of the ripening process in nearly all fruits is softening. Although this is associated with other changes both chemical and physical in nature, the softening of the fruit both on the tree and following picking appears to be one of the most marked changes which occur during the ripening process, particularly with deciduous-tree fruits.

Pressure to determine the maturity of fruits by indentation of the fruit with the thumb has probably been practiced as long as fruits have been eaten by man. The use of a mechanical device to measure the hardness of the fruit was first suggested by O. M. Morris, of the Washington Agricultural Experiment Station. Murneek ${ }^{2}$ and other workers ${ }^{3}$ of the Oregon Agricultural Experiment Station have used such a test to determine the picking maturity of pears and have developed a mechanical apparatus for determining the pressure required to force a rounded plunger of definite dimensions into the fruit for a certain distance. This apparatus has been used to a limited extent for several years for determining the picking maturity of pears in Oregon. The writer and others ${ }^{4}$ have used a slightly modified form of this apparatus in connection with applestorage studies and have found it to give an excellent index of the actual condition of ripeness of the fruit at any time during the storage period. It quickly became apparent, however, that if such an apparatus is to come into general use for determining fruit maturity, an equipment simple in design, easily portable, relatively

2 Murneek, A. E. A new test for the maturity of the pear. Oreg. Sta. Bul. 186. 1921.

a Hartman, Henry. Studies relating to the harvesting and storage of apples and pears. Oreg. Sta. Bul. 206. 1924.

- Magness, J. R., and Burroughs, A. M. Storage Investigations, 1921-22. The Marble Laboratory (Inc.).

- and Diehl, H. C. Physiological studies on apples in storage. Journ. of Agr. Research, vol. 27, No. 1, G-347. 1924. 
inexpensive, and convenient to use is necessary. The purpose of this circular is to describe such an apparatus.

\section{DESCRIPTION OF THE APPARATUS}

A general assembled drawing of the pressure tester is shown in Figure 1, with details of the various parts in Figure 2. The apparatus consists of a barrel $(\mathrm{N})$ within which works a plunger $(\mathrm{G})$ attached to the barrel by a steel tension spring $(\mathrm{J})$. At the end of the plunger rod is the plunger tip (C) which penetrates the fruit. One end of the spring $(J)$ is attached to the upper end of the plunger rod $(G)$, while the other end is attached to the cap (H), which screws on to the end of the barrel, as illustrated. The plunger works freely through the cap $(\mathrm{H})$. When the plunger tip (C) is placed in contact with the fruit the spring is extended in proportion to the pressure applied on the barrel at $\mathbf{M}$. The pressure is then read in pounds on the scale on the milled side of the barrel. The sleeve (K), the lower end of which is turned down slightly to reduce the size and painted black as indicated, is attached to the top of the plunger rod and fits loosely over the spring. The sharp line between the black paint and the metal surface, termed the "indicator line," which moves directly under the milled slot $(\mathrm{O})$, is the point which shows the number of pounds of pressure being applied.

Details of construction of the plunger tip and the collar (A) surrounding it are shown in Figure 2. As the plunger tip (C) penetrates the fruit, the collar is pushed up until it comes in contact with the disk (F). A small flashlight is grounded from one side by clamping on to the apparatus as shown. A wire leads from the other side to the insulated ferrule (D). When this ferrule comes into contact with the disk (F) it completes the circuit and lights the flashlight. Consequently, when the plunger has penetrated to a certain definite depth, the flashlight is lighted, and the number of pounds pressure required to force the plunger tip into the fruit for that depth is read directly on the scale.

\section{DETAILS OF MANUFACTURE}

There are certain precautions and suggestions regarding the manufacture of the equipment which may be made, based on rather extensive experience with this type of instrument. The barrel (N) is made of stock half-inch brass pipe, the inside of which should be carefully smoothed out. The sleeve (K) which works within this pipe should fit very loosely, with an outside diameter at least one sixty-fourth of an inch less than the inside diameter of the pipe. This is necessary to reduce friction. The spring $(J)$ should in turn fit loosely in the sleeve $(K)$ and about the plunger rod $(G)$, to reduce friction.

Considerable difficulty has been experienced in holding the spring (J) firmly attached to the cap $(\mathrm{H})$. The end of the spring should pass through the cap and then over sideways to the edge of the cap, where it is bent down, as shown in Figure 1, and soldered in place. Where a smaller end has been used the tension and twisting of this end of the spring have resulted in the spring breaking loose from the soldering. Then, as tension is applied, the spring slips sideways and in some cases has come into contact with the plunger rod, resulting 


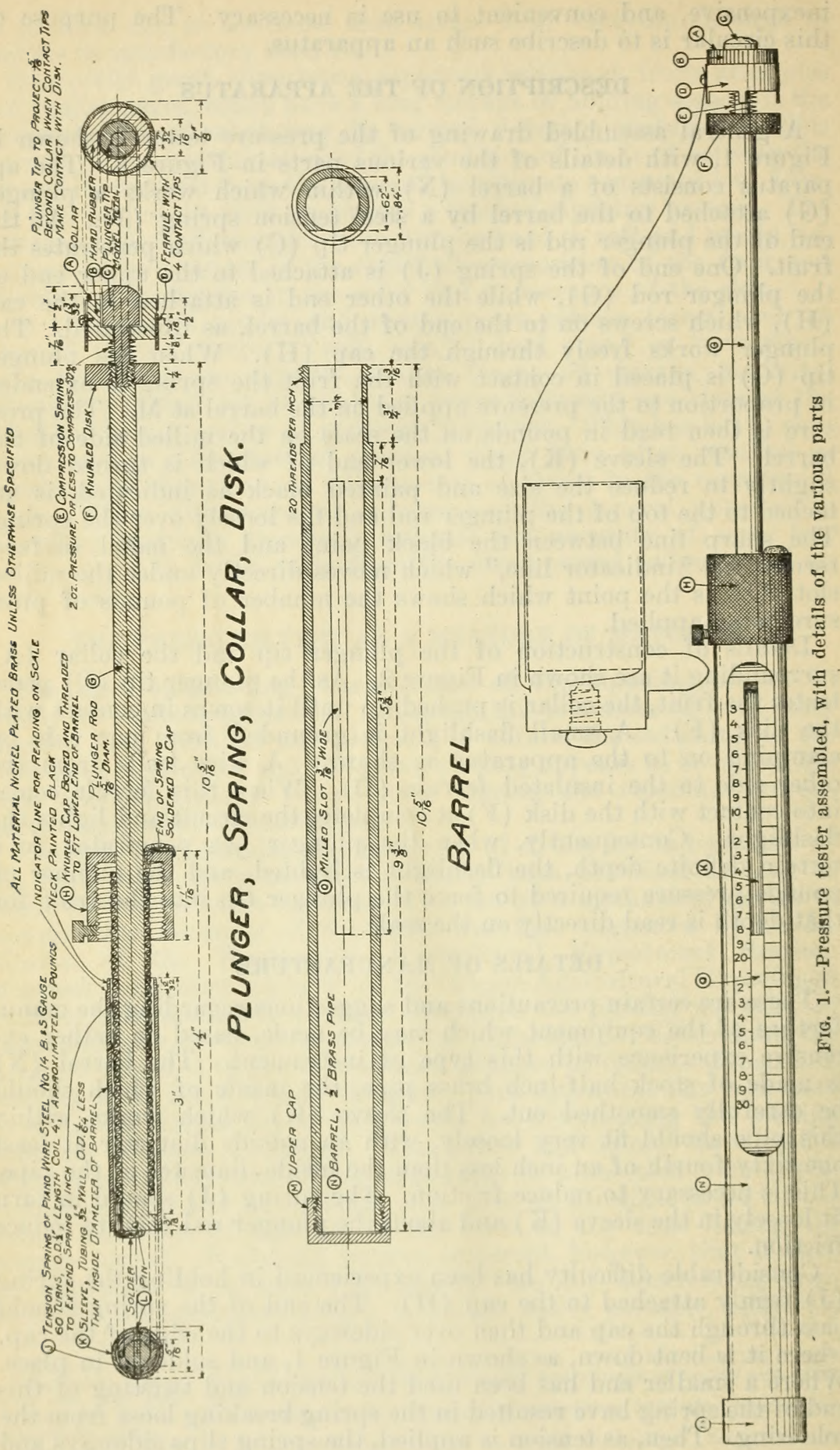


in markedly increased friction and inaccurate readings. ${ }^{5}$ This trouble has not been encountered when an ample end has been left for soldering the spring firmly in place.

The plunger rod $(G)$ should fit loosely through the opening in the cap $(\mathrm{H})$. This cap and the end of the barrel are designed as illustrated in order to adjust the zero point of the apparatus. The plunger tip is made of monel metal, since brass may not always he sufficiently stiff to prevent bending. Steel, on the other hand, would corrode in the fruit juices to which this portion of the apparatus is continually exposed. By using contact tips, as shown on the collar, all difficulty with poor contact due to the presence of fruit juice, etc., has been eliminated.

\section{ESSENTIALS OF MANUFACTURE}

While the equipment as a whole should be very carefully made, there are certain details which should be given particular care. The cross-section area and depth to point of contact of that portion of the plunger which penetrates the fruit should be checked carefully. The curvature of the plunger tip should closely approximate that

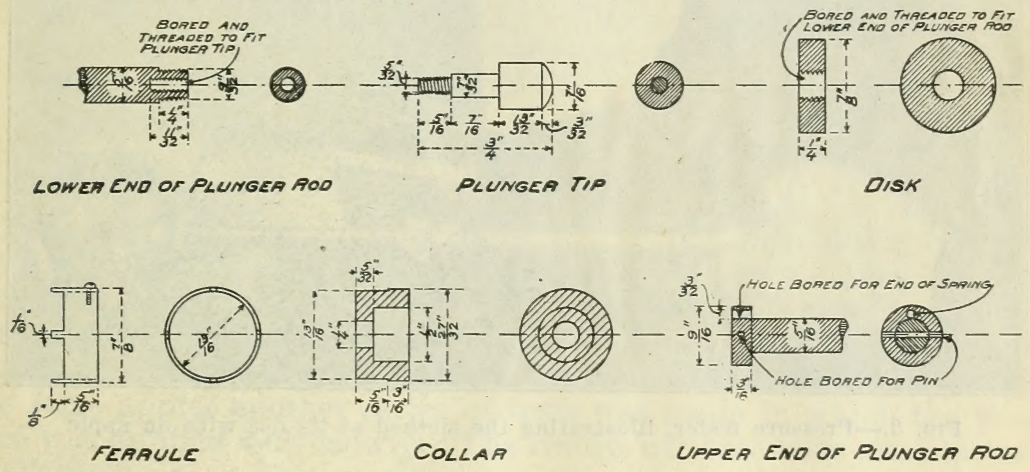

FIG. 2.-Details of various parts of the pressure tester

shown. Slight variations in the shape of the surface of the plunger tip have been found to have practically no effect on the test, so long as the projected cross area of the plunger tip is correct. The spring which determines the number of pounds pressure being applied should be of the best grade piano-wire steel and when extended by the application of pressure should work freely and easily. It should be carefully calibrated by putting the end of the plunger on an accurate platform scale, pressing down until the scale registers a certain number of pounds, and marking accordingly. When the tester is being used it is important to check the reading from time to time by testing with a platform scale, as heretofore described. An adjustment in the reading is possible by loosening the set screw and moving the cap $(\mathrm{H})$ up or down.

\section{USE OF THE PRESSURE TESTER ON APPLES}

So far this type of tester has been fairly extensively used only on apples, and the suggestions relative to methods of use are par-

5 Since this description was written, this difficulty has been overcome by using a threaded cap on which the spring itself is screwed. 
ticularly applicable to this fruit, though they may be equally pertinent to the testing of others.

The use of the apparatus is illustrated in Figure 3. The skin of the apple to be tested is first removed by slicing off an area one-half to three-quarters of an inch in diameter, because the skin tends to mask the actual condition of the flesh of the apple, as will be shown later. The fruit is then placed against a wall or any convenient surface, and the end of the plunger is directed squarely against the cut surface. The opposite end of the apparatus rests against the hand, as illustrated, and pressure is applied until the plunger penetrates the fruit sufficiently to push the collar (A) up against the disk (F). This completes the circuit, lighting the flashlight. The number of pounds indicated on the scale when the light flashes is recorded.

The dimensions of the plunger here shown have been found very satisfactory for the testing of apples, particularly for determining the storage maturity of the fruit. They closely approximate those of the Oregon Agricultural Experiment Station tester. For certain fruits plungers of smaller cross section or depth of penetration may

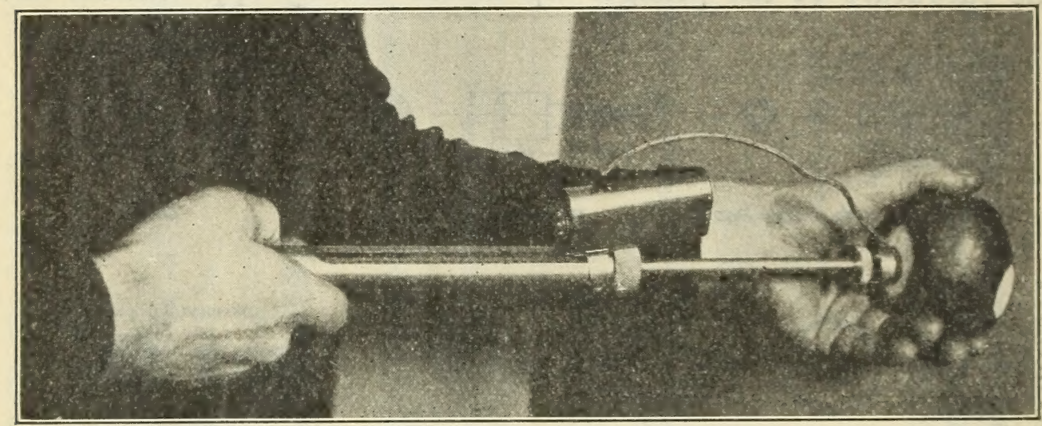

FrG. 3.-Pressure tester, illustrating the method of its use with an apple

be desirable. If so, they can be developed readily on the same general principle, or plunger tips of varying sizes can be used with the instrument here described.

\section{EFFECT OF TESTING WITH AND WITHOUT PEEL REMOVED}

In Table 1 are reported certain data from specific tests which serve to emphasize the necessity of testing apples with the peel removed. Tests made at the time of picking several varieties with and without the peel removed are recorded, together with tests of similar fruit when in prime eating condition. All of the data here reported are averages of the determinations of 25 apples, and the tests when the fruit was in prime eating condition were made on fruit of the same pick and from the same trees as that made at the time of picking.

A comparison of the difference between the tests made with and without the peel removed shows that, with the exception of McIntosh, every variety showed a greater difference due to the skin when the fruit was soft or in prime eating condition than at the time of picking. In most cases the difference in the soft fruit, depending on whether or not the peel was removed, was practically double that found in fruit at picking time, showing that the skin tends to mask 
the softening of the fruit and that the tests with the skin intact portray the actual condition of the flesh much less accurately than those with the skin removed.

TABLE 1.-Comparison of testing, with and without peel removal, the maturity of apples

\begin{tabular}{|c|c|c|c|c|c|c|}
\hline \multirow{3}{*}{ Variety } & \multicolumn{6}{|c|}{ Test of pressure applied to fruit (pounds) } \\
\hline & \multicolumn{3}{|c|}{ At time of picking } & \multicolumn{3}{|c|}{$\begin{array}{l}\text { When in prime eating } \\
\text { condition }\end{array}$} \\
\hline & $\begin{array}{l}\text { Peel } \\
\text { removed }\end{array}$ & $\begin{array}{l}\text { Peel not } \\
\text { removed }\end{array}$ & $\begin{array}{l}\text { Differ- } \\
\text { ence }\end{array}$ & $\begin{array}{l}\text { Peel } \\
\text { removed }\end{array}$ & $\begin{array}{l}\text { Peel not } \\
\text { removed }\end{array}$ & $\begin{array}{l}\text { Differ- } \\
\text { ence }\end{array}$ \\
\hline $\begin{array}{l}\text { McIntosh } \\
\text { Grimes Golden } \\
\text { Delicious } \\
\text { Stayman Winesap } \\
\text { Rome Beauty } \\
\text { King David. } \\
\text { Baldwin } \\
\text { Ben Davis } \\
\text { Winesap } \\
\text { Yellow Newtown } \\
\text { Arkansas (Mammoth Black Twig) }\end{array}$ & $\begin{array}{l}13.5 \\
17.9 \\
15.8 \\
16.2 \\
17.4 \\
18.0 \\
18.1 \\
19.0 \\
20.1 \\
19.9 \\
23.0\end{array}$ & $\begin{array}{l}18.2 \\
19.5 \\
18.3 \\
19.4 \\
20.5 \\
19.3 \\
19.2 \\
22.2 \\
24.4 \\
28.8 \\
27.2\end{array}$ & $\begin{array}{l}4.7 \\
1.6 \\
2.5 \\
3.2 \\
3.1 \\
1.3 \\
1.1 \\
3.2 \\
4.3 \\
8.9 \\
4.2\end{array}$ & $\begin{array}{r}8.1 \\
9.3 \\
9.9 \\
9.8 \\
11.2 \\
10.4 \\
9.8 \\
11.6 \\
10.1 \\
15.8 \\
12.8\end{array}$ & $\begin{array}{l}12.8 \\
11.8 \\
16.7 \\
18.1 \\
16.9 \\
13.3 \\
16.5 \\
17.5 \\
18.6 \\
27.6 \\
21.0\end{array}$ & $\begin{array}{r}4.7 \\
2.5 \\
6.8 \\
8.3 \\
5.7 \\
2.9 \\
6.7 \\
5.9 \\
8.5 \\
11.8 \\
8.2\end{array}$ \\
\hline
\end{tabular}

- Not quite prime eating condition.

\section{INFLUENCE OF RATE OF APPLICATION OF PRESSURE ON PRESSURE-TEST RESULTS}

It is realized that in the hands of various individuals the rate of application of pressure in testing fruit will vary somewhat. To determine what the effect of this would be upon the readings, a series of tests was made in which the pressure was applied so rapidly that it was impossible to read the scale with entire accuracy. On the same apples another series of tests was made in which the pressure was applied very slowly. The results of these tests are reported in Table 2.

TABLE 2.-Influence of slow and rapid application of pressure on results secured with the tester in determining the firmness of apples

\begin{tabular}{|c|c|c|c|}
\hline \multirow{2}{*}{ Variety } & \multicolumn{3}{|c|}{ Pressure in pounds } \\
\hline & $\begin{array}{c}\text { Rapid } \\
\text { test }\end{array}$ & Slow test & $\begin{array}{l}\text { Differ- } \\
\text { ence }\end{array}$ \\
\hline $\begin{array}{l}\text { Winesap } \\
\text { Stayman Winesap. } \\
\text { Ben Davis... }\end{array}$ & $\begin{array}{l}16.0 \\
12.1 \\
13.9\end{array}$ & $\begin{array}{l}15.8 \\
11.6 \\
13.3\end{array}$ & $\begin{array}{r}0.2 \\
.5 \\
.6\end{array}$ \\
\hline
\end{tabular}

It is apparent that there is some difference due to the rate of application of the pressure. Ben Davis showed the greatest difference (six-tenths of a pound) as the average on a lot of 25 apples. Since these figures represent the greatest possible extremes, the rate of application of the pressure is apparently a less important factor than might be supposed. So long as the pressure is applied at a rate sufficiently slow to be read accurately little variation due to this cause will be found. 


\section{RANGE OF PRESSURES IN APPLES AS TESTED BY THIS TYPE OF EQUIPMENT}

Table 3 gives in summary form the ranges of pressures which have been found for a number of the important commercial apple varieties at the time of picking, when the fruit is in prime eating condition, and when the fruit would generally be considered past prime eating condition.

TABLE 3.-Approximate range of pressures of important commercial varieties of apples between the time of picking and the time of full ripeness as me sured by the pressure-test apparatus, all tests being for fruit with peel removed

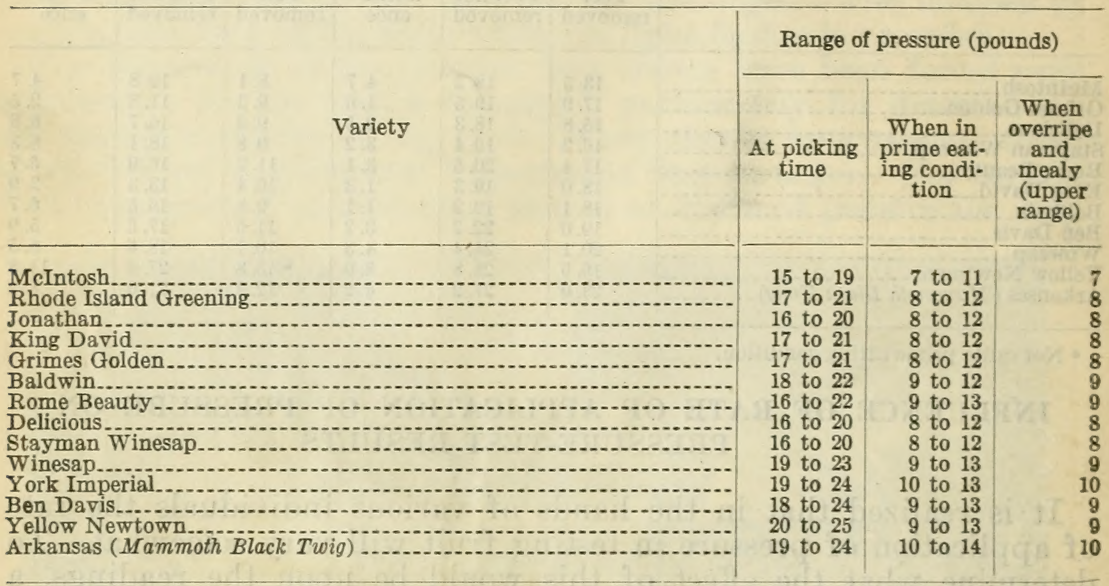

It is evident that there is considerable range in the different varieties at the time they are generally picked. The same variety grown in northern districts will usually be somewhat harder at picking time than if grown in southern districts. There is also a marked variation in the maturity at the time of picking with individual growers. The ranges of pressures given are not reported with the idea that they should be followed as picking tests but rather as the approximate ranges which will be found under present picking conditions.

In Table 3 are reported the ranges of pressures when the fruit is in prime eating condition. The lower range in this respect for the different varieties represents a rather soft but not mealy eating condition, while the upper range represents about the highest point at which most people find the frut sufficiently soft for eating. These figures have been obtained without particular regard to what the general fruit trade considers "firm " or "ripe," since the interpretation of these terms varies greatly with different individuals.

In the last column of Table 3 is given the range at which the fruit is generally past prime eating condition. Only the upper range of pressure is given for each variety, since the fruit may go down from this to 2 or 3 pounds as it breaks down and disintegrates. These figures will serve as a guide, however, until more elaborate data are available relative to the pressure tests of the different varieties. 




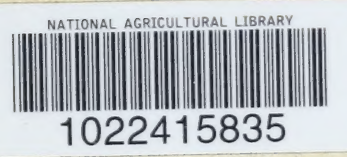


